\title{
Effectiveness of the Advertisement through Television
}

Dil Krishna Shahu, M.Phil.

Lecturer, Trubhuvan University

Email: shahudil12@gmail.com

\begin{abstract}
Television advertisement has become a permanent means of delivering product and service messages to all upper and middle class households. The study aims at examining effectiveness of TV advertisement. Online survey with structured questionnaire was conducted through the various social media. Sample sizes of 150 people are selected for the study by using random sampling method to collect the data to avoid biasness in the selection process. The study found that the people are more attracted toward the use of internet. Most people tend to spend less time watching television and more time on internet and other activities. It is concluded that there is lack of effectiveness of television advertisements in modern era.
\end{abstract}

Keywords: effectiveness, advisement, internet, purchase decision

\section{Introduction}

Popularization of the product is the basic aim of advertising (Fatima \& Lodhi, 2015). The mass media is the most commonly used for their marketing communications. Advertisements that help the advertiser to reach its goals are considered as effective advertisements (Doyle \& Saunders, 1990). The choice of media relies upon the nature of the message and the intended target audience. Among various forms of advertisement, television advertising is considered as a popular and powerful medium of information and entertainment to reach the audiences. Television advertising has been a popular medium ever since the television appears as one the most common items in living rooms with the arrival of cable television. As production costs is comparatively lower and high opportunity to reach smaller and more targeted markets, it has become a medium for small to medium sized business programmes like song, news, interviews, comedy and information attracts the largest audience than any other medium. The benefit of television over the other mediums is that it is perceived as a combination of video and audio features; it offers products with instant validity and prominence and offers the greatest possibility for creative advertising (Fatima \& Lodhi, 2015).

Since the long time ago, the Television set has become a permanent fixture in all upper and middle class households. Further, it is common even in the poorer society of urban areas and rural households. Television advertisement has the prime effects on viewers 
8 THE BATUK : A Peer Reviewed Journal of Interdisciplinary Studies $\quad$ Vol. 6 Issue No. 2 July 2020 ISSN 2392-4802

and persuades them to start acquiring processes and has solid influence on consumers' perception (Joloudar, Yaser, \& Ansari, 2011). Reactions to TV advertisements seem to be stronger than the reaction to print advertisements. The advertisers find it more effective to use television rather than print media to reach consumers, partly due to low literacy rate. TV advertising not only change emotions but give substantial message exerting a far reaching influence on the daily lives of people. Advertisement is desired to provide messages to individuals who are interested in their products or services.

Television has often been criticized for being a nonselective medium, since it is difficult to reach a precisely defined market segment through the use of TV advertising (Belch, Belch \& Purani, 2009). But some selectivity is thinkable due to differences in the composition of audiences as a result of program content, program time, and geographic coverage (Belch, Belch \& Purani, 2009). Due to technical development, opportunities to advertise on TV have increased over the past years. The consumers are open to hundreds and thousands of commercial messages a day. The people's willingness to watch advertisement in TV is reducingdue to various reasons. They do not watch carefully all the advertisement.Likewise, not all the ads are skipped by them, ads which have some entertainment value are liked, watched and remembered by audience which is a welcome response for the ad makers (Krishnakumar \& Radha, 2014). The basic idea of advertising is to inform, educate and motivate potential buyers. In this era, the media of advertisement matters a lot. In urban areas, TV is still the most effective medium of advertisement in persuading the viewer that it has become the most reliable channel of promoting products, both existing and newly launched ones.

Consumers have been largely exposed to the TV advertising as the main media used by advertisers to provide information. However, over the years marketing strategies have evolved with technology leading to the internet creating unprecedented opportunities for marketers to connect with the customers to create an immersive connected digital situation, influence and drive purchases, fuel new growth and create new market share. The growth of internet advertising both globally and locally is outpacing TV advertisements. While outdoor advertising is also experiencing significant growth, the effectiveness of advertisement on television is under concern. Finally, the question over the effectiveness of TV advertisements has risen. Thus, the study aims at examining effectiveness of Television advertisement in the context of Nepal.

\section{Literature Review}

Television advertisement is a best way to promote goods and services in front of millions of consumers (Abideen \& Saleem, 2011). Television advertisement has the principal effects on viewers and persuades them to start purchasing processes and has strong 
impact on consumers' perception. It was shown that the demand for the advertised products is heavily influenced by the children's attitude towards advertisements. Further, the cognitive changes amongst the various age groups lead to the formation of varying attitudes towards the ads. Feelings and perception regarding a specific product consist of those factors which affected purchaser mind in terms of its cultural values and beliefs. Television is considered major source in presenting the cultural values of any society (Abideen \& Saleem, 2011). Culture is part of us which covers every part of our lives from what we eat to what we wear and the way we feel about others around us (Hyun, Kim, \& Lee, 2011). It was found that almost 75 percent of the respondents had seen the program regularly for interest and or for informative reasons; significantly more people who said they watched for education could recollect parenting methods than those who said they watched for entertainment. Respondents approved that the program informed them about different methods for managing the behaviors of their children $(88 \%)$ and said they had used $(53 \%)$ or intended to use $(23 \%)$ a number of those techniques.

Scholars have also detected that advertising may evoke both the negativeand positive emotions when looking for to persuade. Indeed, many researchers suggested that from a practical perspective, "the relative strength of positive and negative feeling effects potentially could guide advertisers' decisions regarding executioner strategies." It has been suggested that advertisements use positive touch to make consumers like the advertisement and then buy the product, and negative affect to evoke an uncomfortable state that makes consumers want the "solution" offered by the advertiser.

\section{Research Methods}

Descriptive research design has been used. Online survey with structured questionnaire collected through social media like messenger, facebook, viber etc. was conducted to examine effectiveness of television advertisement. Questionnaire includes respondents profile and series of multiple choices and yes/no question. Sample sizes of 150 people are selected for the study by using random sampling method to collect the data to avoid biasness in the selection process.

\section{Results and Analysis}

\section{Demographic Characteristics of Respondents}

Table 1 presents characteristics of respondents based on gender, marital status, age and academic qualification. Majority of respondents are male, i.e. 58.67 percent are male and 41.33 percent are female. 
Table 1

Demographic Characteristics of Respondents

\begin{tabular}{lll}
\hline Gender & Frequency & Percentage \\
\hline Male & 88 & 58.67 \\
Female & 62 & 41.33 \\
Total & 150 & 100 \\
\hline Marital status & & \\
Single & 84 & 56 \\
Married & 66 & 44 \\
Total & 150 & 100 \\
\hline Age (years) & & \\
Below 20 & 45 & 30 \\
20-35 & 66 & 44 \\
35-50 & 24 & 16 \\
Above 50 & 15 & 10 \\
Total & 150 & 100 \\
\hline Academic Qualification & & 100 \\
SLC & 30 & 20 \\
Intermediate & 18 & 12 \\
Undergraduate & 66 & 44 \\
Post graduate & 24 & 16 \\
No formal education & 12 & \\
Total & 150 & \\
\hline
\end{tabular}

Fifty six percent of respondents are single. Based upon age wise, the highest age group of respondent is 35-50 years and lowest age group of the respondents is above 50 years. The table also depicts that most of the respondents (44\%) holds undergraduate degree, followed by $20 \%$ who passed SLC.

\section{Time Spent on Watching Television Vs Internet Surfing}

The Table 2 presents time the respondents spend on watching television and internet surfing daily. Sixty percent of people spend less than 1 hour on watching television in a day, followed by 20 percent who spend 1 to 2 hours daily. Likewise, 12 percent of respondents spend 2 to 3 hours on watching television. Whereas 8 percent of respondents tend to spend more than 3 hours in front of television set. These results may be the effect 
of mobile phones, internet and travelling that has reduced the culture of spending time on watching television. Similarly 42 percent of the respondents spend more than 4 hours on internet daily. This is followed by 24 respondents who spend 3-4 hours daily on internet. A number of respondents who spend less than 1 hour on internet is 12 percent of total responses.

Table 2

Time Spent on Watching Television vs Internet Surfing

\begin{tabular}{llllll}
\hline \multirow{2}{*}{ Duration of Time } & \multicolumn{2}{c}{ Watching Television } & & \multicolumn{2}{c}{ Internet Surfing } \\
\cline { 2 - 3 } \cline { 5 - 6 } \cline { 5 - 6 } & Frequency & Percentage & & Frequency & Percentage \\
\hline Less than 1 hour & 90 & 60 & & 18 & 12 \\
1 to 2 hours & 30 & 20 & & 33 & 22 \\
2 to 3 hours & 18 & 12 & & 36 & 24 \\
More than 4 hour & 12 & 8 & & 63 & 42 \\
Total & 150 & 100 & & 50 & 100 \\
\hline
\end{tabular}

\section{Factors Attracting Attention towards TV Commercials}

The Table 3 presents the possible factors in TV commercials that tend to attract the attention of the consumer. The table indicates animation as a most effective factor that pulls consumers attention towards TV commercial. It constitutes 30 percent of the total responses. TV commercials with Jingle constitute 21 percent, and with celebrity endorsement constitutes 26 percent of the total responses. The least effective factor in all these is humour, as it only measures 20 percent of total responses. This clearly shows that marketers should focus more on creating animated commercials to gain the attention of consumers.

Table 3

Factors Attracting Attention towards TV Commercials

\begin{tabular}{lll}
\hline Factors Creating Attention & Frequency & Percentage \\
\hline Jingle & 32 & 21 \\
Celebrity endorsement & 37 & 25 \\
Animation & 45 & 30 \\
Humour & 36 & 24 \\
Total & 150 & 100 \\
\hline
\end{tabular}


12 THE BATUK : A Peer Reviewed Journal of Interdisciplinary Studies $\quad$ Vol. $6 \quad$ Issue No. 2 July 2020 ISSN 2392-4802

\section{Influencing Components of Commercial Advertisement}

The Table 4 presents components that influence the respondents in a commercial advertisement. The results provide the evidence that theme as major components that influence the consumers in commercial advertisements. Thirty three percent of the total response is influenced with the theme of commercial advertisement followed by model, which constitutes 31 percent. While the least effective components is contents, as it only measures 14 percent.

Table 4

Influencing Components in Commercial Advertisement

\begin{tabular}{lll}
\hline Influencing Components & Frequency & Percentage \\
\hline Theme & 49 & 33 \\
Content & 21 & 14 \\
Background & 34 & 23 \\
Models & 31 & 31 \\
Total & 150 & 100 \\
\hline
\end{tabular}

\section{Reaction of Respondents towards TV Advertisement}

Table 5 presents reaction of respondents towards TV advertisement. The table shows that majority $(73 \%)$ of the respondents choose to skip the channel during the commercial break. They aren't interest in watching advertisement. On the other hand, only 27 percent of respondents watch the advertisement during commercial break. This could be the result of dissatisfaction among people due to content, creativity and duration of TV advertisements.

Table 5

Reaction of Respondents towards TV Advertisement

\begin{tabular}{lll}
\hline Reaction & Frequency & Percentage \\
\hline Watch the advertisement & 41 & 27 \\
Skip the channel & 109 & 73 \\
Total & 150 & 100 \\
\hline
\end{tabular}

\section{Effectiveness of TV Commercial}

The Table 6 presents the effectiveness of TV advertisement. It is found that 57 percent of the respondents purchase decision are unaffected by TV advertisement. In the same way, 43 percent of the respondents believe that their purchase decisions are influenced by TV advertisement. The results support that majority of the respondents skip channel while 
playing advertisement. Table 7 also presents the results of respondents on finding best products through TV advertisement. Fifty four percent of the respondents believe that TV advertisement doesn't help or assist them in finding the best products. The other 46 percent believes that TV commercials help them to find the best products in the market. There is almost a similar opinion towards TV advertisements.

Table 6

Effectiveness of TV Commercial

\begin{tabular}{lccc}
\hline Does TV advertising influence your purchase decision? & Yes & No & Total \\
\hline Number & 72 & 78 & 150 \\
Percentage & 43 & 57 & 100 \\
\hline Does TV advertising help you to find the best products? & & & \\
\hline Number & 69 & 81 & 150 \\
Percentage & 46 & 54 & 100 \\
\hline
\end{tabular}

Time length of TV Commercials to Create Attention and Impact

Table 7 presents desirable length of time for TV commercials to create attention and impact on the consumers. Majority (52\%) of respondent think that TV advertisements should be within the range of 30 seconds to 1 minute. Whereas, 43 percent of the respondents believe that TV advertisement should be less than 30 seconds so that it can attract their attention and also be impactful. Four percent of the respondents think that advertisements should be within the range of 1 to 2 minutes, and other 4 percent like long duration advertisement i.e. higher than 2 minutes. The results are in accordance with table 2 which shows the time respondents spend on watching TV and reaction to advertisements respectively.

Table 7

Length of TV Commercials to Create Attention and Impact

\begin{tabular}{lll}
\hline Length of Time & Frequency & Percentage \\
\hline Less than 30 seconds & 20 & 43 \\
30 second to 1 minutes & 24 & 52 \\
1 to 2 minutes & 3 & 4 \\
2 minutes and above & 3 & 4 \\
Total & 150 & 100 \\
\hline
\end{tabular}




\section{Conclusion}

The people are more attracted toward to use of internet. most people tend to spend less time watching television and more time on internet and other activities. Hence it can be concluded that there is lack of effectiveness of television advertisements in modern era. This is the result of disappointment faced by large number of people upon buying products/services by the influence of TV advertisements. Other major findings also depicts that the duration of advertisement and its components also influences the reaction of people towards TV advertisement. Less the duration of advertisements, more people watch it and vice-versa. This is concluded from the findings that people watch advertisement when its duration is short, else they skip the channel. At the same time, people are also affected by what's shown in TV advertisement. It can be concluded that most people prefer animated advertisements in television. Though most television advertisements are informative through audio and video presentation, it is still important to ensure that there is no complexity in understanding what advertisements want to inform. Marketers should focus on making television advertisements short and informative. Less the duration of advertisements, more people are likely to watch it. People are more influenced by the animated factor in television advertisements. Hence, the advertisements agencies should focus on creating animated content to increase the effectiveness of television advertisements. The information given in advertisements is sometimes false and tries to misguide consumers. Thus, advertisers should refrain from such activity and give out correct and clear advertisements so that television advertisements assist people to find best products. Advertising company should serve consumers with what's shown in advertisements. Consumers shouldn't feel cheated by purchasing products/services depending upon the advertisement.The findings of this study will benefit advertising company and agency to gain insight into what consumers prefer to see in television so that their advertisements become effective despite emergence of other advertising means.

\section{References}

Abideen, Z.-U., \& Saleem, S. (2011). Effective advertising and its influence on consumer buying behavior. European Journal of Business and Management, 3(3), 55-65.

Belch, G. E., Belch, M. \& Purani, K. (2009). Advertising and Promotion. Tata McGraw Hill Education Private limited, New Delhi.

Doyle, P., \& Saunders, J. (1990). Multiproduct advertising budgeting. Marketing Science, 9(2), 97-113. http://dx.doi.org/10.1287/mksc.9.2.97 
Fatima, S., \& Lodhi, S. (2015). Impact of Advertisement on Buying Behaviours of the consumers: Study of Cosmetic Industry in Karachi City. International Journal of Management Sciences and Business Research, 4(10).

Hoque, N. (2013). Impact of TV advertisements on the "Response Process "of the private service holders of Bangladesh. Business and Economic Research, 3(1).

Hyun, S. S., Kim, W., and Lee, M. J. (2011). The impact of advertising on patrons' emotional responses, perceived value, and behavioral intentions in the chain restaurant industry: The moderating role of advertising-induced arousal.

International Journal of Hospitality Management, 30(3), 689-700.

Joloudar, E., Yaser, S., \& Ansari, M. E. (2011). An Investigation of TV Advertisement Effects on Customers' Purchasing and Their Satisfaction, International Journal of Marketing Studies, 3(4).

Krishnakumar, K., \& Radha, K. (2014). A Study on Relevance Factor in Effectiveness of Television Advertisements on Consumer Purchase Decision in Salem District. International Journal of Business and Administration Research Review, I(2).

Krugman, H. E. (1969). The Impact of Television Advertising: Learning without Involvement. Public Opinion Quarterly, 29, 349-356.

Romaniuk, J., \& Sharp, B. (2004). Conceptualizing and measuring brand salience. Marketing Theory, 4(4), 327-342. 